Research Article

\title{
Triaxial Shear Behavior of a Gravelly Sand with Different Forms of Reinforcement
}

\author{
Jia-Quan Wang $\left(\mathbb{D},{ }^{1}\right.$ Sen-Lei Hou, ${ }^{1}$ Jian-Feng Xue $\mathbb{D}^{2,3}{ }^{2,3}$ Zh-Nan Lin, ${ }^{1}$ and Yi Tang ${ }^{1}$ \\ ${ }^{1}$ College of Civil and Architectural Engineering, Guangxi University of Science and Technology, Liuzhou 545006, China \\ ${ }^{2}$ School of Engineering and IT, University of New South Wales, Canberra 2612, Australia \\ ${ }^{3}$ Visiting Scholar, Fujian YonKing Geotechnical Co., Ltd., Longyan 364000, China \\ Correspondence should be addressed to Jian-Feng Xue; jianfeng.xue@adfa.edu.au
}

Received 17 September 2020; Revised 28 January 2021; Accepted 2 February 2021; Published 18 February 2021

Academic Editor: Jia-wen Zhou; jwzhou@scu.edu.cn

Copyright (c) 2021 Jia-Quan Wang et al. This is an open access article distributed under the Creative Commons Attribution License, which permits unrestricted use, distribution, and reproduction in any medium, provided the original work is properly cited.

\begin{abstract}
To study the effect of three-dimensional reinforcement arrangement on the behavior of a gravelly sand, triaxial tests were performed on specimens reinforced with geogrid sheet, geogrid cell, and one and two layers of geogrid sheet and geocell combination. Specimens with a diameter of $100 \mathrm{~mm}$ and a height of $200 \mathrm{~mm}$ are sheared under drained condition to monitor the variation of axial and volumetric strains with axial loading under different confining pressures. The results showed that the reinforcement schemes have different effects on soil strength improvement. The inclusion of double layers of geogrid sheet and geocell reinforcement could increase both the apparent cohesion and friction of the reinforced soil. The stress-strain relationship could be modelled with a modified hyperbolic model, which can capture the softening strain behavior of the specimens after peak strength.
\end{abstract}

\section{Introduction}

Gravelly sand has been widely used in geotechnical engineering, such as pavement base material. As an uncemented granular material, with minimal cohesion, such soil needs to be reinforced in many cases to improve its performance [1-7]. Different types of reinforcing mechanisms have been used in practice. Most research studies on the application of reinforced structures have been focused on horizontal reinforcement. Jiang et al. [8] studied the mechanical properties of the reinforced coarse-grained soil with hexagonal reinforcement network through the large-scale triaxial test and found that the strength and stiffness of the coarse-grained soil can be significantly improved after reinforcement. Abdelkader et al. [9] explored the influence of geotextile on the stress-strain and volume variation characteristics of reinforced sand through the triaxial test and found that the geotextile could increase the shear strength and reduce the expansion of the specimens. Carlos et al. [10] used filament nonwoven fabric as reinforcing material and studied the effect of reinforcement on fine-grain soils using triaxial tests. It was found that nonwoven fabric provided additional constraints to the soil and increased the strength of the specimens. Al Subari et al. [11] carried out consolidated undrained triaxial tests on sand reinforced with coir and found that the addition of coir reinforcement has increased the shear strength of the reinforced sand. Markou [12] studied the influence of particle shape and size on the mechanical properties of geotextile-reinforced sand and found that the strength of the reinforced specimens with angular grains is higher than that of round grains. Chen et al. [13] found that the deformation of geogrid-reinforced coarse-grained mudstone in triaxial shear tends to follow strain hardening behavior. Kim and Ha [14] studied the effect of particle size on direct shear characteristics of geogrid-reinforced coarsegrained soils and found that the inclusion of geogrid could reduce the friction angle of the soils, as geogrid could reduce the interlocking between soil particles under direct shear condition. Bao et al. [15] studied the working mechanism of geogrid-reinforced soil through triaxial test and numerical analysis and pointed out that the reinforcing effect of 
reinforcement is generated by the interface constraint between reinforcement and soil particles.

Vertical reinforcement has been used in many forms to improve the apparent cohesive resistance of encased soils, such as geosynthetic-encased stone columns [16-21] or clay with vertical reinforcement [22], and geocell [23-25]. Latha and Murthy [26] performed triaxial tests on sand reinforced with horizontal reinforcement, geocells, and randomly distributed discrete fibers and found that the cellular form of reinforcement is more effective in improving the strength of the sand. Song et al. [27] performed a series of large-scale triaxial compression tests on sandy soil of different relative densities confined with circular geocell. The authors found that the reinforcement effect is more significant for dense sand than that for loose sand at medium strain levels, and geocell-reinforced loose sand shows a strain hardening behavior at large strain levels. The stress-strain relationship of the geocell-soil composites follows a hyperbolic nonlinear model.

To study the combination effect of horizontal and lateral reinforcement, Zhang et al. [28, 29] proposed the concept of $\mathrm{H}-\mathrm{V}$ (horizontal-vertical) orthogonal reinforcing elements to provide passive resistance against shearing. The authors performed a comprehensive set of triaxial tests on dry sand reinforced with $\mathrm{H}-\mathrm{V}$ orthogonal and vertical elements. It was found that the inclusion of $\mathrm{H}-\mathrm{V}$ orthogonal reinforcing elements could increase the friction angle effectively but slightly in apparent cohesion. This is different from the findings that encasement could increase the apparent cohesion of stone columns [30, 31], and horizontal reinforcement could potentially increase both apparent cohesion and friction angle if multiple layers are used [32].

Existing research shows that there is little study on the combination of horizontal reinforcement sheets and vertical reinforcement cells as reinforcement in soils. The existing studies on 3D reinforcement have been focused on reinforcements made with galvanized iron, rubber, and Perspex $[28,29]$. There is little research on geogrid as $3 \mathrm{D}$ reinforcement for soils. Considering this, this paper studies the effect of including both horizontal and vertical reinforcement on the behavior of a gravelly sand. Geogrid sheet and geogrid cells are used as horizontal and vertical reinforcement in $100 \mathrm{~mm}$ diameter and $200 \mathrm{~mm}$ in height soil specimens. Four reinforcement forms including the combination of horizontal reinforcement sheet and vertical reinforcement cell were adopted in the tests to study the effect of reinforcement arrangement and reinforcement layers on the behavior of the soils. The specimens were sheared under triaxial loading. The variations of axial and volumetric strains of the specimens with loading were monitored. A modified hyperbolic model is proposed to describe the softening strain behavior of the specimens after peak strength.

\section{Materials and Methods}

2.1. Materials Used in the Tests. The soil used in the tests is a well-graded gravelly sand bought from a commercial supplier in Liuzhou, China. The particle size distribution of the soil is shown in Figure 1. The coefficient of uniformity $(\mathrm{Cu})$ is 5.38 and the curvature coefficient $(C c)$ is 1.16. According to the Unified Soil Classification System (USCS), the soil can be classified as well-graded sand with gravel (SW). The grains are mostly angular. The maximum and minimum dry bulk densities of the soil are $18.21 \mathrm{kN} / \mathrm{m}^{3}$ and $15.97 \mathrm{kN} / \mathrm{m}^{3}$, respectively. The specific gravity of the soil particles is 2.67 . Biaxial HDPE geogrid with a mesh size of $20 \mathrm{~mm} \times 20 \mathrm{~mm}$ was used as the reinforced material. The properties of the geogrid are shown in Table 1.

The tests were performed on a universal cyclic triaxial loading system. The loading system has a maximum axial loading capacity of $10 \mathrm{kN}$. The maximum confining pressure and back pressure of the system are both $2 \mathrm{MPa}$.

2.2. Experimental Scheme and Procedure. To study the effect of reinforcing arrangement on reinforced soil behavior, three reinforcement schemes were used in the tests: one layer of geogrid square sheet (with a diagonal length of $100 \mathrm{~mm}$ as shown in Figure 2(a)), $70 \mathrm{~mm}$ diameter geogrid cell (Figure 2(b)), and the combination of geogrid cell and geogrid sheet (Figure 2(c)). To prepare a geogrid cell, a geogrid strip is rolled into a ring along the length direction so that two cells are overlapping. The overlapped ribs are tied with fine steel wire as shown in the figure. Compared with the method of bonding the overlapped mesh with epoxy resin [14], this method is simpler and closer to the common methods used in practice. In the combination reinforcement layout, there is no connection between the geogrid sheet and the geogrid cell. Four reinforcement schemes shown in Figure 3 are studied. In addition, one set of tests were performed on specimens with no reinforcement.

To prepare the specimens, the soils were oven-dried and compacted in 5 layers in a $100 \mathrm{~mm}$ inner diameter and $240 \mathrm{~mm}$ high split mold. A latex membrane is installed inside the split mold and placed onto the pedestal of the triaxial device. A porous stone disc was placed on top of the pedestal before raining soil into the split mold for compaction. According to the Code for Design of Railway Earth Structure (TB10001-2016), the compaction coefficient (the ratio of the density of the soil to its maximum density) of railway subgrade should be greater than 0.97 , which gives a minimum relative density of 0.85 as used in the tests. To achieve this value, each layer is compacted with a wood tamper with 30 blows. Once a specimen is prepared, a porous stone disc is placed on the top surface of the soil column before fixing the specimen to the loading pad and removing the split mold. Considering the minimum relative density required in the standards, the effect of relative density is not studied in the tests. The specimens were saturated to the Skempton $B$ value of 0.95 using the back pressure system in the triaxial cell. According to the Standard for Geotechnical Testing Method (GB/T50123-2019), for triaxial compression test on noncohesive coarse-grained soils, the shear rate should be $0.1 \% / \mathrm{min}$, so the specimens were sheared at the rate of $0.2 \mathrm{~mm} / \mathrm{min}$ to reach an axial strain of $15 \%$. Reinforced soil structures are normally high, for example, $20 \mathrm{~m}$ or higher [33]. Considering the stress 


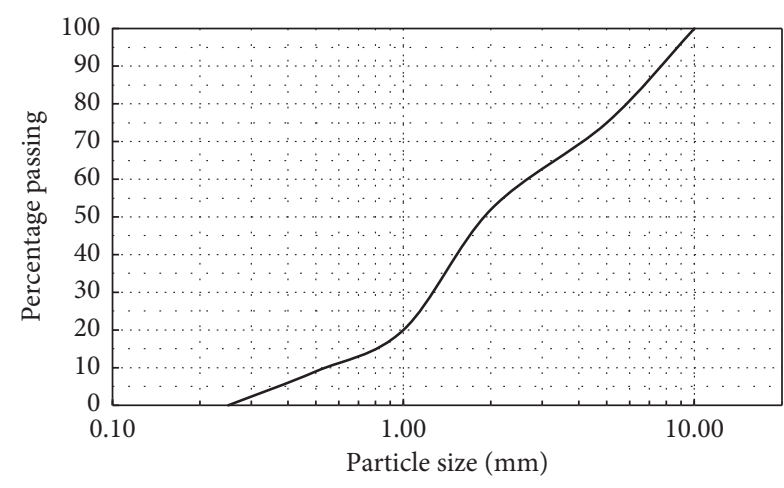

Figure 1: Particle size distribution of the soil.

TABle 1: Properties of the geogrid used in the tests.

\begin{tabular}{lcccc}
\hline Mesh size $(\mathrm{mm})$ & \multicolumn{2}{c}{ Rib width $(\mathrm{mm})$} & \multicolumn{2}{c}{ Tensile strength $(\mathrm{kN} / \mathrm{m})$} \\
& Cross & Longitudinal & Transverse & Longitudinal \\
\hline $20.0 \times 20.0$ & 2.0 & 3.0 & 15.4 & 18.6 \\
\hline
\end{tabular}

levels normally encountered, the confining pressures in the test were set at $50 \mathrm{kPa}, 75 \mathrm{kPa}$, and $100 \mathrm{kPa}$.

\section{Test Results}

3.1. Stress-Strain Curve Analysis. The stress-strain curves of the reinforced specimens follow the same trend as those of the unreinforced specimens, but with greater peak shear strength as shown in Figure 4. For the specimens reinforced with one layer of geogrid sheet and one geogrid cell, the shear behaviors are similar, which may be coincident. The specimens with combination $3 \mathrm{D}$ reinforcement have the greatest peak shear strength. This is because the embedding horizontal geogrid layer would restrain the forming of the shear band in the soil column and the geogrid cell would effectively increase the confining pressure to the soil particles [30]. The combination of both horizontal and the ring cell reinforcement would be much more effective than the use of either method alone. The reinforcing effect of geogrid and geogrid cell combination decreases as confining pressure increases. This is due to the fact that the contribution to confining effect from geogrid cell to soil movement reduces as confining pressure increases. With two layers of combined reinforcement, the reinforcement effect does not decrease much with the increase of confining pressure. This is because the double layer of geogrid sheet may have provided greater resistance to soil movement at higher confining pressures. The figure also shows that the elasticity modulus of the specimens does not change much with the inclusion of reinforcement. This is because the interaction between the geogrid and the soil is maximized when there is relative displacement between the soil and the reinforcements. At the early stage of the tests, the shear displacement is too small to activate the reinforcing effect; therefore, the shear behavior of the specimens is similar at lower strain levels. The strain level for the specimens to reach peak strength varies around $3 \%$. This may suggest that the relative movement between soil particles still controls the strain at failure of the specimens.

Figure 4 shows that including one layer of geogrid sheet and one geogrid cell is almost similar in improving soil strength. The apparent cohesion $(c)$ and the friction angle $(\phi)$ of the specimens are compared in Table 2 . The results show that including one layer of geogrid sheet and a geogrid cell could double the apparent cohesion of the soil, but increase the friction angle by about $10 \%$. By including one layer of combination reinforcement, greater effect can be seen in apparent cohesion improvement. When including 2 layers of combination reinforcements, both the friction angle and apparent cohesion of the soil can be improved, by about $20 \%$ and $300 \%$, respectively. This indicates the effectiveness of multiple layers of combination reinforcement on soil strength improvement.

3.2. Volumetric Strain Analysis. The relationship between the volumetric strain $\varepsilon_{v}$ and the axial strain $\varepsilon_{1}$ of the gravelly soil specimen with different reinforcement schemes under various confining pressures is shown in Figure 5. All the reinforced specimens exhibited great dilation behavior. The comparison shows that, with the inclusion of reinforcement, the volumetric strain of the soils could be reduced and the reduction of volumetric strain in the specimen with combination reinforcement is the greatest (about 30\%). Again the $\varepsilon_{v}$ and $\varepsilon_{1}$ relationships of the specimens with one layer of geogrid sheet and with one geogrid cell are similar. The reduction of volumetric strain is the greatest in the specimen with two layers of combined reinforcement. Before reaching the peak strength, i.e., $\varepsilon_{1}<4 \%$, the dilations of the specimens are very small $(<3 \%)$.

\section{Stress and Strain Relationship of Reinforced Gravelly Soil}

Hyperbola models have been widely used to describe the strain development of sandy soils [34]. The model proposed by Duncan and Chang [35] is one of the popular models that require fewer parameters:

$$
\sigma_{1}-\sigma_{3}=\frac{\varepsilon_{1}}{a+b \varepsilon_{1}}
$$

The results of the triaxial tests are replotted in $\varepsilon_{1} /\left(\sigma_{1}-\right.$ $\left.\sigma_{3}\right)$ and $\varepsilon_{1}$ space in Figure 6.

It is found that the relation of $\varepsilon_{1} /\left(\sigma_{1}-\sigma_{3}\right)$ and $\varepsilon_{1}$ can be better described with a parabola function rather than a linear function:

$$
\sigma_{1}-\sigma_{3}=\frac{\varepsilon_{1}}{\left(a+b \varepsilon_{1}\right)^{2}}
$$

Meanwhile, the model describing contraction and dilatation phenomena proposed by Shen [36]:

$$
\varepsilon_{v}=\frac{\varepsilon_{1}\left(\mathrm{~d} \varepsilon_{1}+c\right)}{\left(e \varepsilon_{1}+c\right)^{2}}
$$




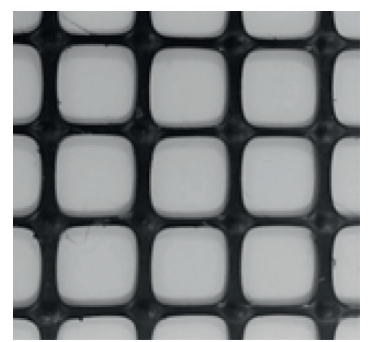

(a)

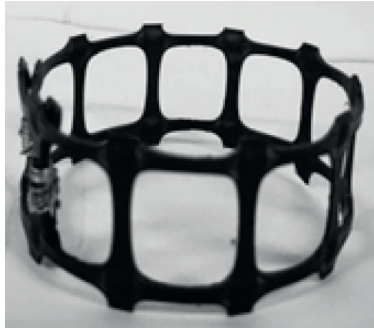

(b)

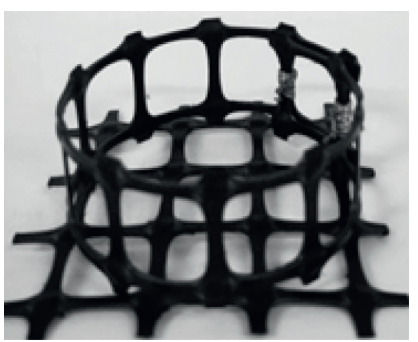

(c)

Figure 2: Different forms of reinforcement: (a) geogrid sheet, (b) Geogrid cell, and (c) combination.

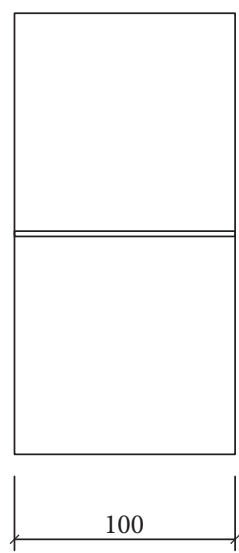

(a)

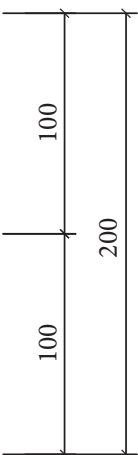

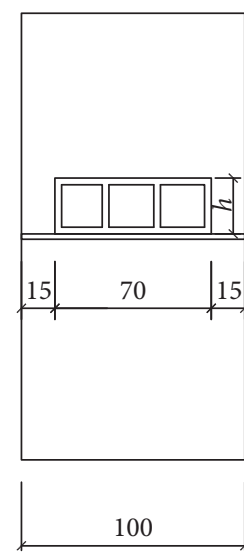

(b)

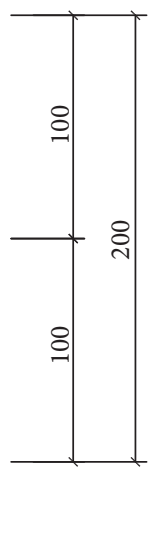

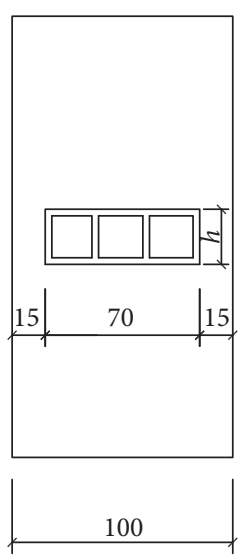

(c)

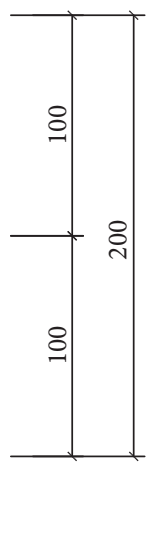

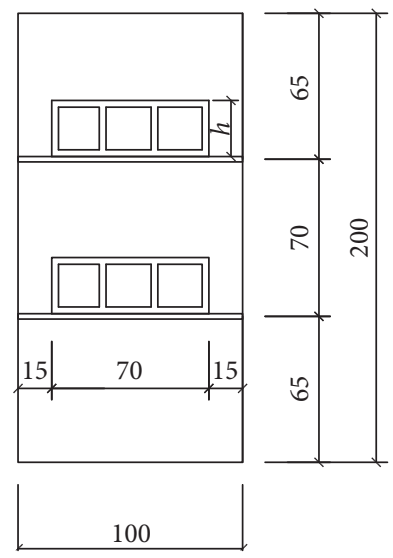

(d)

Figure 3: Arrangement of reinforcement schemes in the tests (dimensions are in $\mathrm{mm}$ ): (a) geogrid sheet, (b) geogrid cell, (c) one layer of combination 3D reinforcement, and (d) two layers of combination 3D reinforcement.

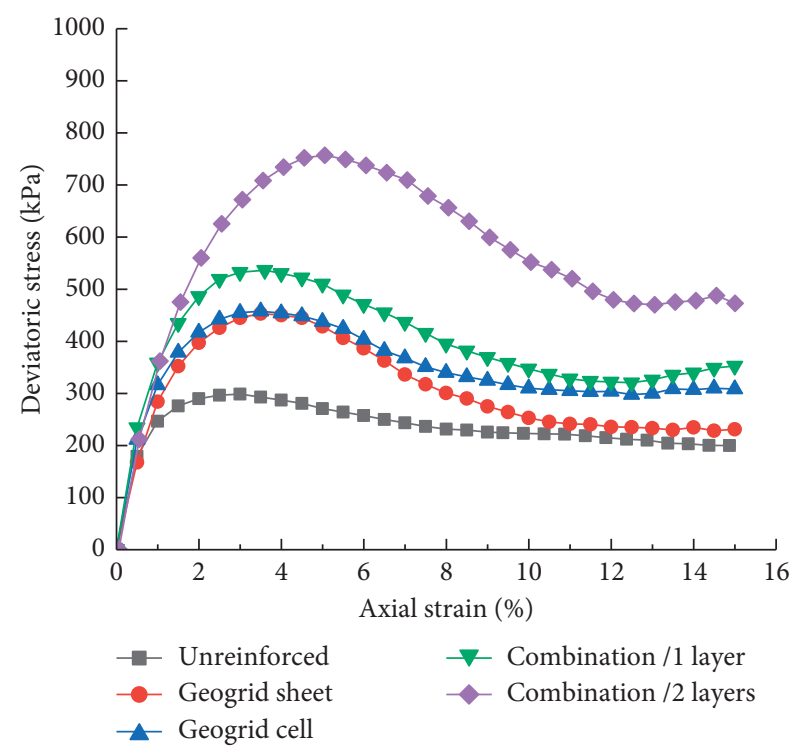

(a)

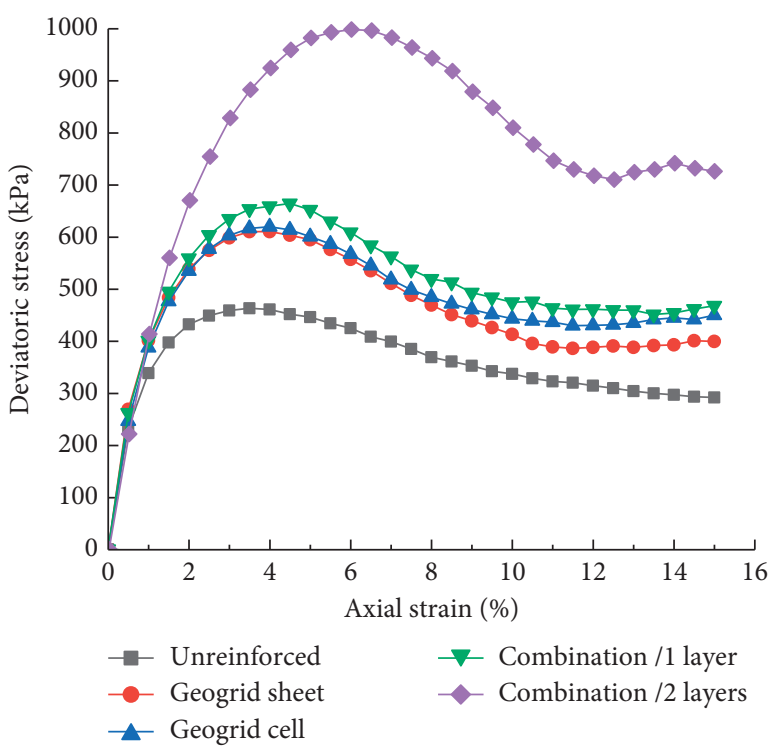

(b)

Figure 4: Continued. 


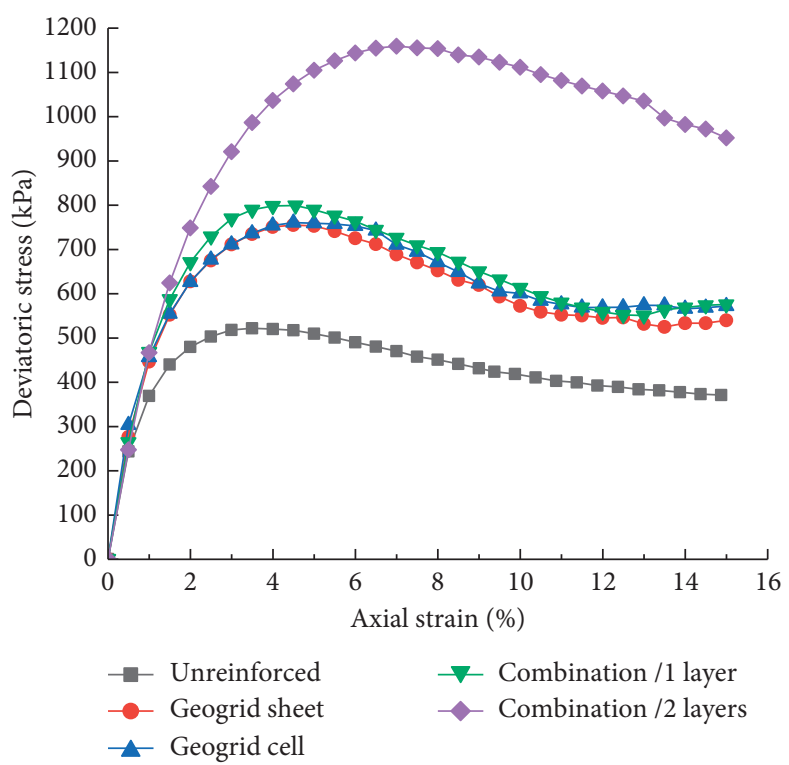

(c)

Figure 4: Deviatoric stress versus axial strain curves under different reinforcement forms. (a) $\sigma_{3}=50 \mathrm{kPa},(\mathrm{b}) \sigma_{3}=75 \mathrm{kPa}$, and (c) $\sigma_{3}=100 \mathrm{kPa}$.

TABLE 2: Strength indices of the soil specimens: the apparent cohesion $(c)$ and friction angle $(\phi)$.

\begin{tabular}{lcc}
\hline Reinforcement scheme & $c(\mathrm{kPa})$ & $\phi\left(^{\circ}\right)$ \\
\hline Unreinforced & 15.9 & 44.5 \\
One layer of geogrid sheet & 29.6 & 48.8 \\
One geogrid cell & 28.8 & 48.7 \\
One layer of geogrid composite & 53.9 & 46.4 \\
Two layers of geogrid composite & 59.9 & 53.4 \\
\hline
\end{tabular}

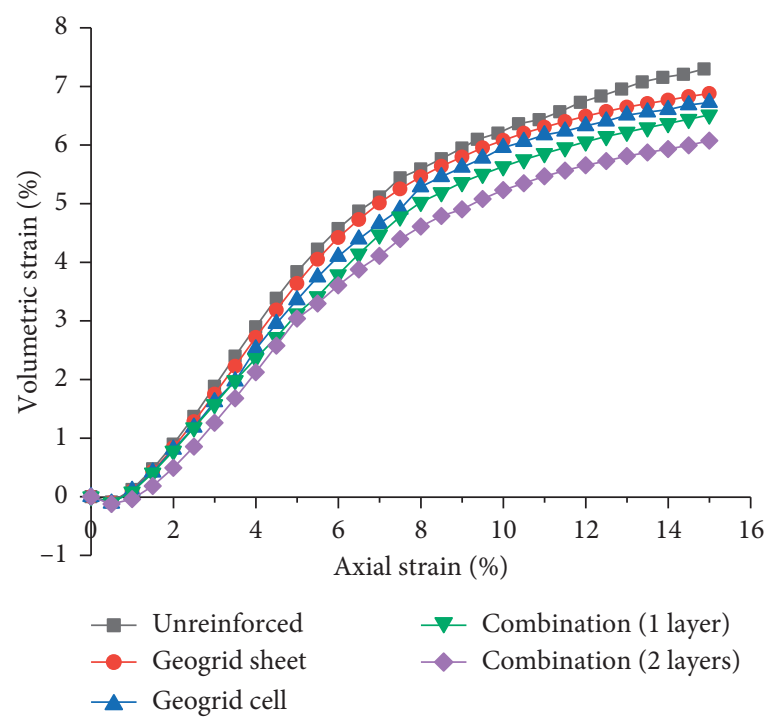

(a)

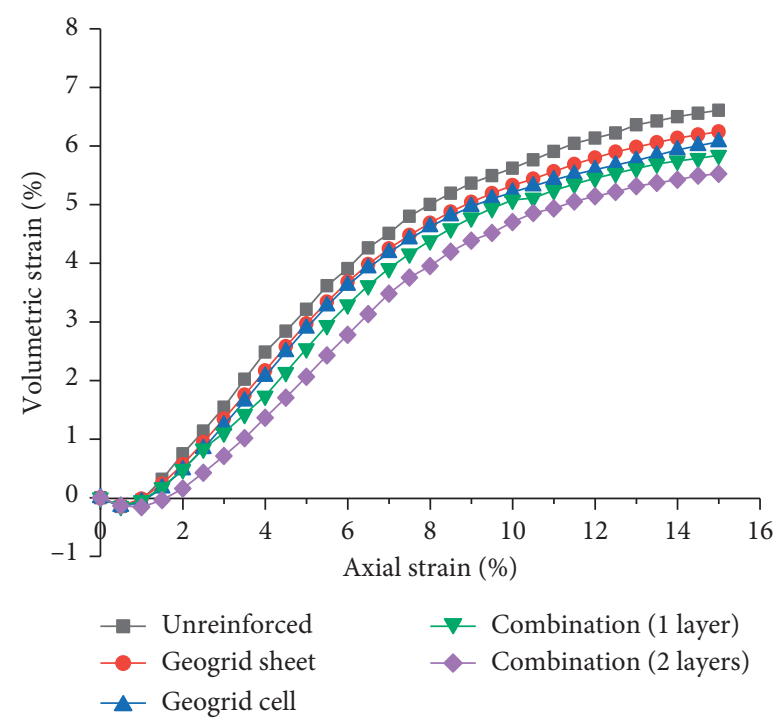

(b)

Figure 5: Continued. 


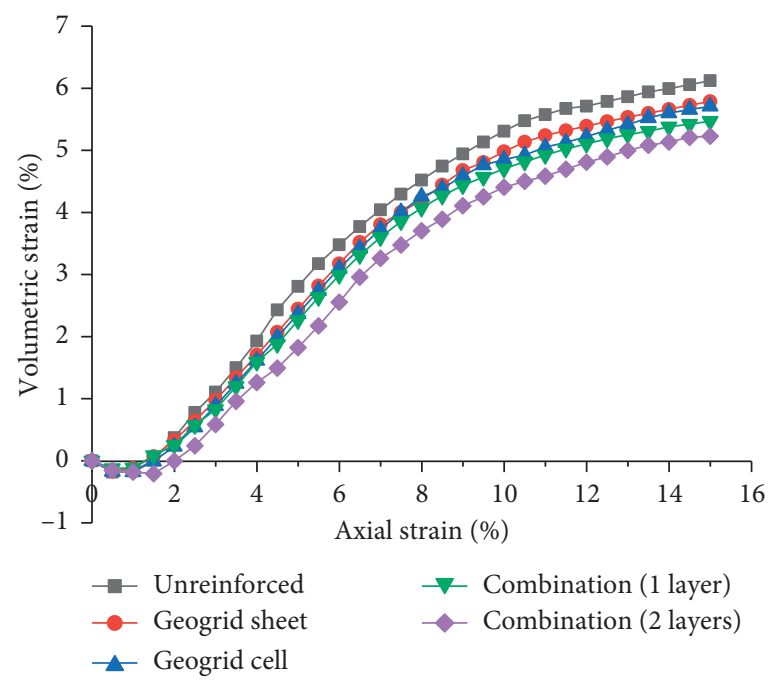

(c)

Figure 5: Volumetric strain and axial strain curves in different reinforced forms: (a) $\sigma_{3}=50 \mathrm{kPa}$, (b) $\sigma_{3}=75 \mathrm{kPa}$, and (c) $\sigma_{3}=100 \mathrm{kPa}$.

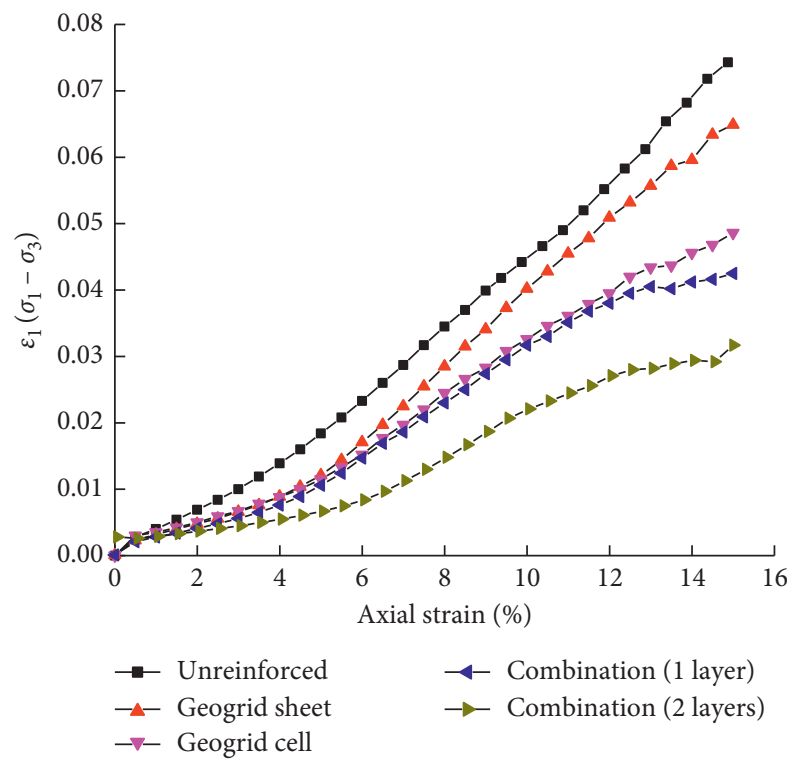

(a)

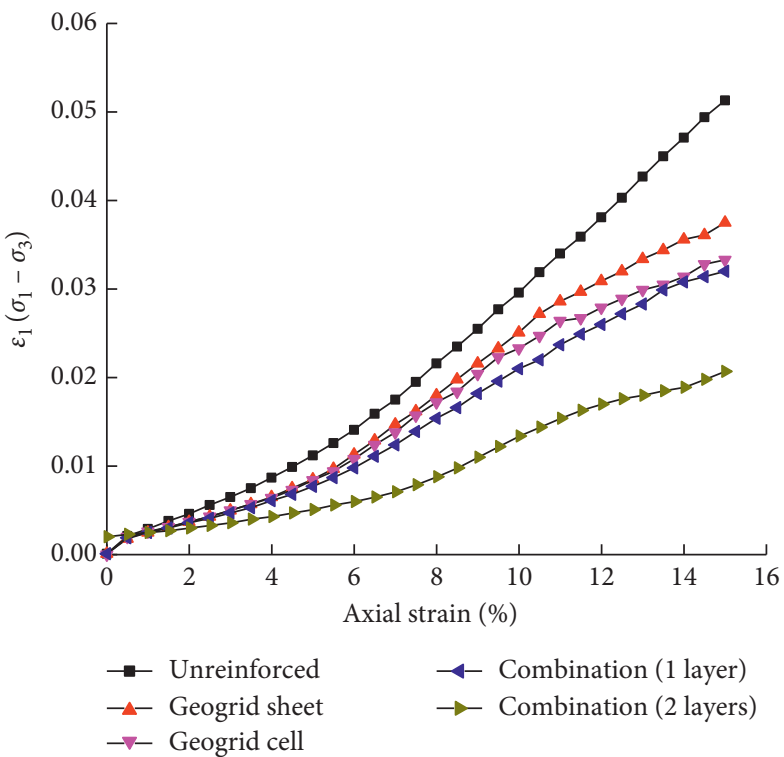

(b)

Figure 6: Continued. 


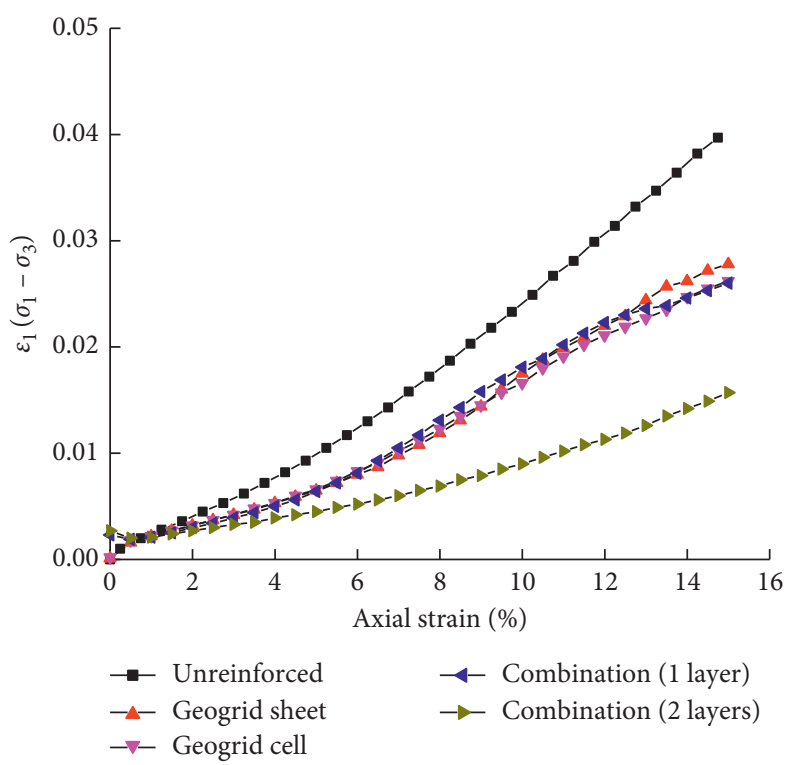

(c)

FiguRe 6: $\varepsilon_{1} /\left(\sigma_{1}-\sigma_{3}\right)-\varepsilon_{1}$ curves of sand under different confining pressures: (a) $\sigma_{3}=50 \mathrm{kPa}$, (b) $\sigma_{3}=75 \mathrm{kPa}$, and (c) $\sigma_{3}=100 \mathrm{kPa}$.

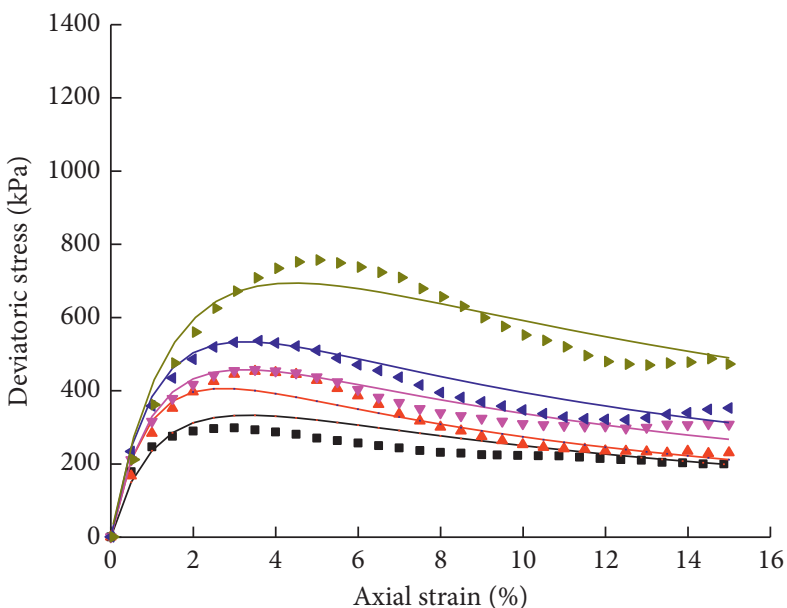

- Unreinforced

- Geogrid sheet

- Geocell

- Combination (1 layer)

- Combination (2 layers)

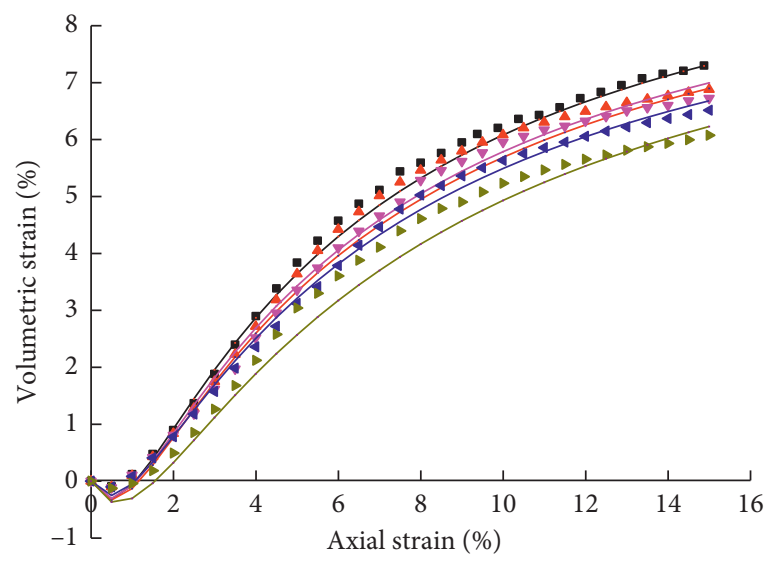

- Unreinforced
- Geogrid sheet

- Geocell

4 Combination (1 layer)

- Combination (2 layers)

- Unreinforced fitted Geogrid sheet fitted Geocell fitted

- Geogrid sheet fitted

Geocell fitted (1 layer) fitted Combination (2 layers) fitted (a) (b)

Figure 7: Continued. 

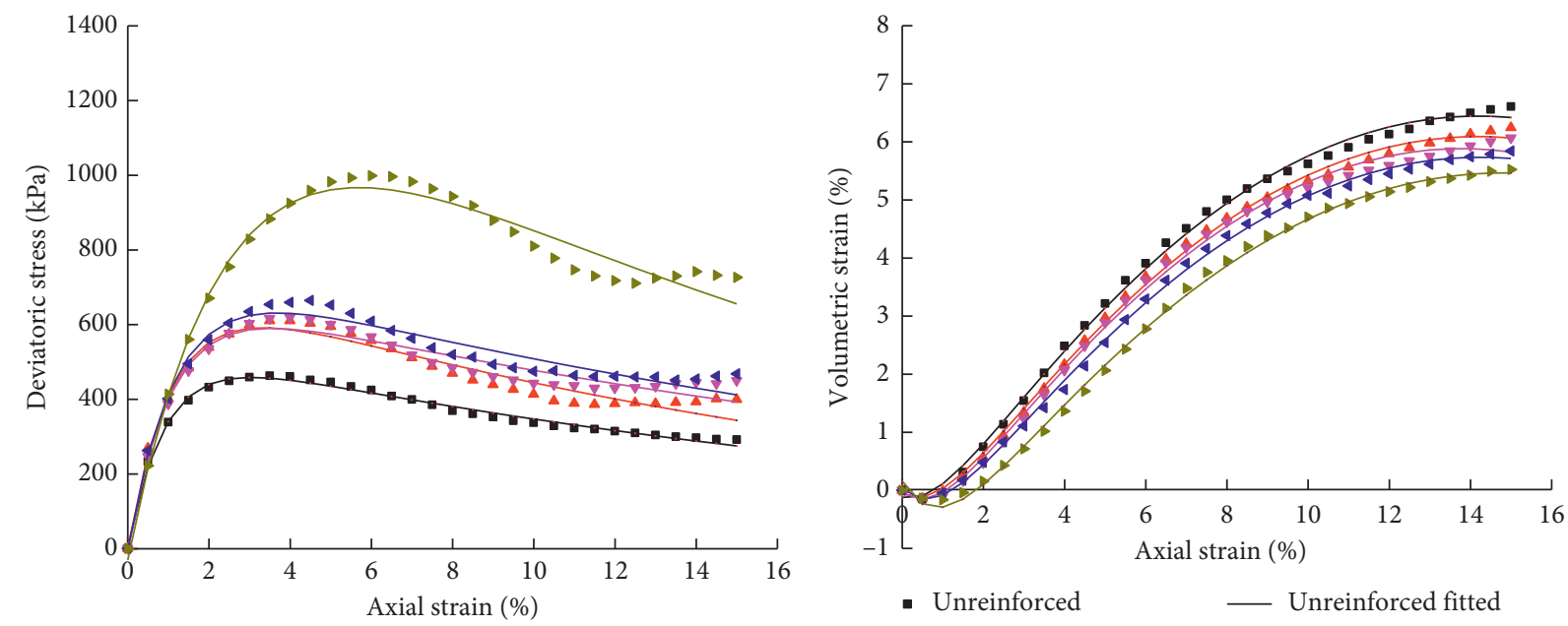

- Unreinforced

- Geogrid sheet

- Geocell

4 Combination (1 layer)

- Combination (2 layers)

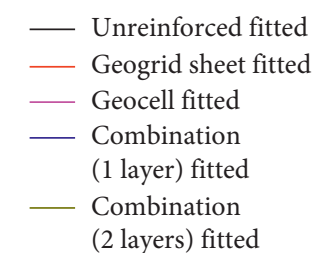

(c)

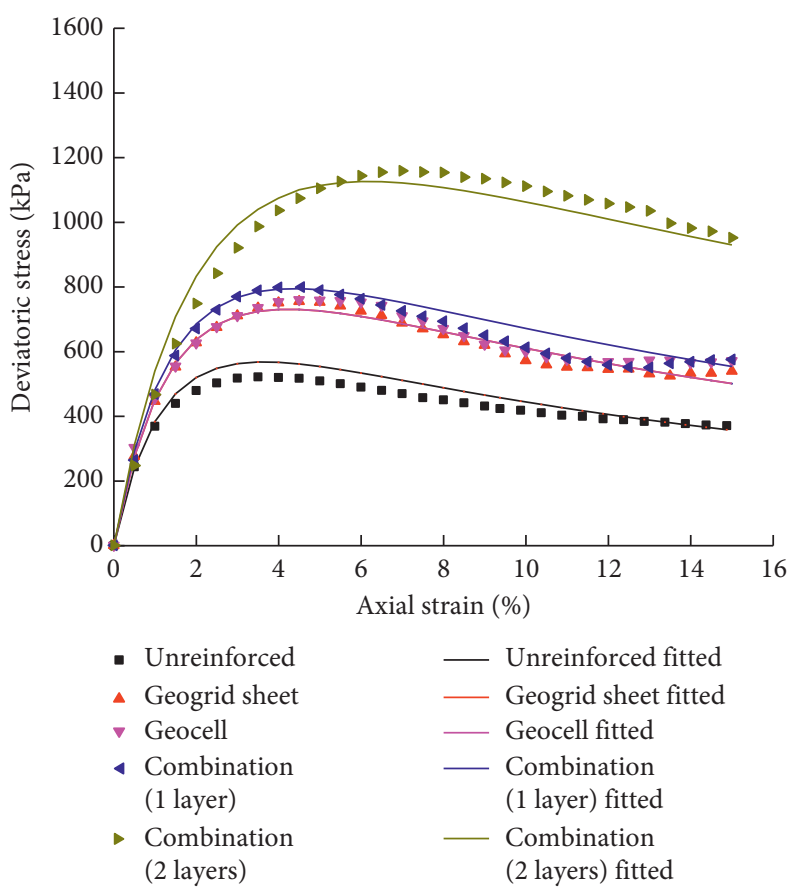

(e)
- Unreinforced

$\Delta$ Geogrid sheet

- Geocell

4 Combination (1 layer)

- Combination (2 layers)

$$
\begin{aligned}
& \text { —- Unreinforced fitted } \text { Geogrid sheet fitted } \\
&- \text { Geocell fitted } \\
& \text { - Combination } \\
& \text { (1 layer) fitted } \\
&- \text { Combination } \\
& \text { (2 layers) fitted }
\end{aligned}
$$

(d)

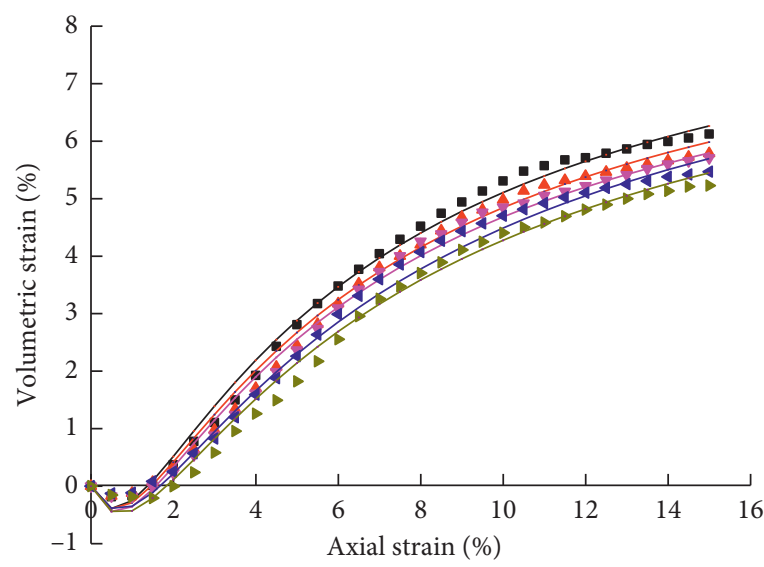

- Unreinforced

- Geogrid sheet

v Geocell

— Unreinforced fitted

4 Combination (1 layer)

- Combination (2 layers)
— Geogrid sheet fitted

_ Geocell fitted

- Combination (1 layer) fitted

— Combination (2 layers) fitted

(f)

Figure 7: Comparison of tested and modelled $\varepsilon_{1} /\left(\sigma_{1}-\sigma_{3}\right)$ and $\varepsilon_{v} / \varepsilon_{1}$ relationship: (a) $\sigma_{3}=50 \mathrm{kPa},(\mathrm{b}) \sigma_{3}=50 \mathrm{kPa},(\mathrm{c}) \sigma_{3}=75 \mathrm{kPa}$ (d) $\sigma_{3}=75 \mathrm{kPa},(\mathrm{e}) \sigma_{3}=100 \mathrm{kPa}$, and (f) $\sigma_{3}=100 \mathrm{kPa}$. 
TABLE 3: Stress-strain and volumetric strain-axial strain model parameters of the test results.

\begin{tabular}{lcccccc}
\hline Specimen & $\sigma_{3}(\mathrm{kPa})$ & $a$ & $b$ & $c$ & $d$ \\
\hline \multirow{3}{*}{ Unreinforced } & 50 & 0.050 & 0.015 & 0.630 & 0.554 \\
& 75 & 0.044 & 0.013 & 0.604 & 0.501 & 0.230 \\
& 100 & 0.040 & 0.011 & 0.579 & 0.221 \\
Geogrid sheet & 50 & 0.041 & 0.015 & 0.667 & 0.519 & 0.212 \\
\hline \multirow{3}{*}{ Geogrid cell } & 75 & 0.039 & 0.012 & 0.632 & 0.475 & 0.230 \\
& 100 & 0.038 & 0.009 & 0.593 & 0.438 & 0.210 \\
\hline \multirow{3}{*}{ Combination (1 layer) } & 50 & 0.042 & 0.013 & 0.649 & 0.589 & 0.236 \\
& 75 & 0.040 & 0.011 & 0.606 & 0.472 \\
Combination (2 layers) & 100 & 0.038 & 0.009 & 0.558 & 0.373 \\
& 50 & 0.039 & 0.012 & 0.778 & 0.727 \\
& 75 & 0.038 & 0.010 & 0.730 & 0.573 \\
\hline
\end{tabular}

is modified to describe the volumetric strain-axial strain relationship during shearing:

$$
\varepsilon_{v}=\frac{\varepsilon_{1}\left(\mathrm{~d} \varepsilon_{1}-c\right)}{\left(e \varepsilon_{1}+c\right)^{2}} .
$$

In the two equations, $a, b, c, d$, and $e$ are fitting parameters obtained from $\varepsilon_{1} /\left(\sigma_{1}-\sigma_{3}\right)$ and $\varepsilon_{1}$, and $\varepsilon_{v} / \varepsilon_{1}$ and $\varepsilon_{1}$ curves, which can be done easily in Excel spreadsheet.

The variations of $\varepsilon_{1} /\left(\sigma_{1}-\sigma_{3}\right)$ with $\varepsilon_{1}$, and $\varepsilon_{1}$ with $\varepsilon_{\mathrm{v}}$ of the specimens under the confining pressure of $75 \mathrm{kPa}$ predicted using equations (2) and (4) are compared with the test results in Figure 7. The comparison shows that the proposed models can well capture the behavior of the soils, especially the postpeak softening strain behavior. This is different from the hardening behavior predicted with the Duncan-Chang model [35]. The model parameters used for the curves are shown in Table 3.

\section{Conclusions}

A number of triaxial shear tests have been performed on gravelly sand columns $(100 \mathrm{~mm}$ diameter and $200 \mathrm{~mm}$ height) reinforced with geogrid sheet, geogrid cell, and combination of geogrid sheet and cell to study the effect of different reinforcing schemes on the behavior of the specimens. The stress-strain relationship and volumetric strain and axial strain relationship were monitored during the tests. It was found that reinforced specimens exhibit typical dilation shear behavior. Different reinforcing schemes have different effects on strength improvement. A modified Duncan-Chang model is proposed to describe the softening strain of the specimens after peak strength. The dilation of volumetric strain can be described with a modified Shen's [34] model. Based on the limited number of tests on the reinforcement schemes used, it is found that

(1) Including geogrid sheet, geogrid cell, or geogrid sheet and cell combination can improve both the friction angle and apparent cohesion of the soils. Including one layer of geogrid sheet or geogrid cell is similar in improving soil strength parameters. Including one layer of geogrid sheet and geogrid cell combination is more effective in improving apparent cohesion (by 235\%) than improving friction angle (by 5\%). Including two layers of combined layers of geogrid sheet and geogrid cell combination is effective in improving both apparent cohesion (by $300 \%)$ and friction angle $(20 \%)$.

(2) The relationship between $\varepsilon_{1} /\left(\sigma_{1}-\sigma_{3}\right)$ and $\varepsilon_{1}$ can be better described with a parabola function rather than a linear function. The parabola function can well capture the softening strain behavior of the specimens after the peak strength.

\section{Data Availability}

Since the experiment was completed with the support of Guangxi University of Science and Technology, the data used to support the results of this study can be obtained from the first author upon reasonable request via email: wjquan1999@163.com.

\section{Conflicts of Interest}

The authors declare that there are no conflicts of interest regarding the publication of this paper.

\section{Acknowledgments}

This project was funded by the National Natural Science Foundation of China (no. 41962017), the Natural Science Foundation in Guangxi Province of China (no. 2017GXNSFAA198170), the High Level Innovation Team and Outstanding Scholars Program of Guangxi Institutions of Higher Learning of China, the doctoral Foundation of Guangxi University of Science and Technology (no. 03200009), the Guangxi University Young and Middle-aged Teachers' Basic Scientific Research Ability Improvement Project (no. 2020KY08023), and the Innovation Project of Guangxi University of Science and Technology Graduate Education. 
Support received from Fujian 100 Talents Program of Fujian Province, China, is appreciated.

\section{References}

[1] Z. Cao, T. Leslie Youd, and X. Yuan, "Gravelly soils that liquefied during 2008 Wenchuan, China earthquake, Ms = 8.0," Soil Dynamics and Earthquake Engineering, vol. 31, no. 8, pp. 1132-1143, 2011.

[2] M. Rezaeian, P. M. V. Ferreira, and A. Ekinci, "Mechanical behaviour of a compacted well-graded granular material with and without cement," Soils and Foundations, vol. 59, no. 3, pp. 687-698, 2019.

[3] B. Indraratna, N. T. Ngo, and C. Rujikiatkamjorn, "Behavior of geogrid-reinforced ballast under various levels of fouling," Geotextiles and Geomembranes, vol. 29, no. 3, pp. 313-322, 2011.

[4] G. Gao and M. A. Meguid, "Effect of particle shape on the response of geogrid-reinforced systems: insights from 3D discrete element analysis," Geotextiles and Geomembranes, vol. 46, no. 6, pp. 685-698, 2018.

[5] J. Han and J. K. Thakur, "Sustainable roadway construction using recycled aggregates with geosynthetics," Sustainable Cities and Society, vol. 14, pp. 342-350, 2015.

[6] N. T. Ngo, I. Buddhima, and R. Cholachat, "A study of the geogrid-subballast interface via experimental evaluation and discrete element modelling," Granular Matter, vol. 19, no. 3, p. 54, 2017.

[7] D. Bhattacherjee and B. V. S. Viswanadham, "Numerical studies on the performance of hybrid-geosynthetic-reinforced soil slopes subjected to rainfall," Geosynthetics International, vol. 22, no. 6, pp. 411-427, 2015.

[8] J.-Q. Jiang, G.-L. Yang, L.-M. Li, and G.-W. He, "Experimental investigation on mechanical behavior of a hexagonalwire-reinforced granular soil," Arabian Journal for Science and Engineering, vol. 43, no. 4, pp. 1655-1672, 2018.

[9] B. Abdelkader, A. Arab, M. Sadek, and I. Shahrour, "Laboratory investigation of the influence of geotextile on the stressstrain and volumetric change behavior of sand," Geotechnical and Geological Engineering, vol. 36, no. 4, pp. 2077-2085, 2018.

[10] D. M. Carlos, M. Pinho-Lopes, and M. L. Lopes, "Effect of geosynthetic reinforcement inclusion on the strength parameters and bearing ratio of a fine soil," Procedia Engineering, vol. 143, pp. 34-41, 2016.

[11] L. Al-Subari, M. Hanafi, and A. Ekinci, "Effect of geosynthetic reinforcement on the bearing capacity of strip footing on sandy soil," SN Applied Sciences, vol. 2, no. 9, pp. 1-11, 2020.

[12] I. Markou, "Effect of grain shape and size on the mechanical behavior of reinforced sand," Procedia Engineering, vol. 143, pp. 146-152, 2016.

[13] X. Chen, J. Zhang, and Z. Li, "Shear behaviour of a geogridreinforced coarse-grained soil based on large-scale triaxial tests," Geotextiles and Geomembranes, vol. 42, no. 4, pp. 312-328, 2014.

[14] D. Kim and S. Ha, "Effects of particle size on the shear behavior of coarse grained soils reinforced with geogrid," Materials, vol. 7, no. 2, pp. 963-979, 2014.

[15] C. G. Bao, M. Y. Wang, and J. H. Ding, "Experimental study on the working mechanism of grating reinforced soil," Journal of Yangtze River Scientific Research Institute, vol. 30, no. 1, pp. 34-41, 2013.

[16] J. Gniel and A. Bouazza, "Construction of geogrid encased stone columns: a new proposal based on laboratory testing,"
Geotextiles and Geomembranes, vol. 28, no. 1, pp. 108-118, 2010.

[17] M. Ghazavi and J. Nazari Afshar, "Bearing capacity of geosynthetic encased stone columns," Geotextiles and Geomembranes, vol. 38, no. 1, pp. 26-36, 2013.

[18] K. Ali, J. T. Shahu, and K. G. Sharma, "Model tests on single and groups of stone columns with different geosynthetic reinforcement arrangement," Geosynthetics International, vol. 21, no. 2, pp. 103-118, 2014.

[19] Y.-S. Hong, C.-S. Wu, and Y.-S. Yu, "Model tests on geotextile-encased granular columns under 1-g and undrained conditions," Geotextiles and Geomembranes, vol. 44, no. 1, pp. 13-27, 2016.

[20] M. Miranda and A. Da Costa, "Laboratory analysis of encased stone columns," Geotextiles and Geomembranes, vol. 44, no. 3 , pp. 269-277, 2016.

[21] M. Miranda, A. Da Costa, J. Castro, and C. Sagaseta, "Influence of geotextile encasement on the behaviour of stone columns: laboratory study," Geotextiles and Geomembranes, vol. 45, no. 1, pp. 14-22, 2017.

[22] Y. Nie, Y. J. Li, F. H. Hu et al., "Triaxial test on clay with vertical reinforcement," in Proceedings of the 2017 3rd International Forum on Energy, Environment Science and Materials (IFEESM 2017), Shenzhen, China, November 2018.

[23] J. O. A. Netol, B. S. Bueno, and M. M. Futai, "Evaluation of a calculation method for embankments reinforced with geocells over soft soils using finite-element analysis," Geosynthetics International, vol. 22, no. 6, pp. 439-451, 2015.

[24] F. Song, Y.-L. Xie, Y.-F. Yang, and X.-H. Yang, "Analysis of failure of flexible geocell-reinforced retaining walls in the centrifuge," Geosynthetics International, vol. 21, no. 6, pp. 342-351, 2014.

[25] F. Song, H. Liu, H. Chai, and J. Chen, "Stability analysis of geocell-reinforced retaining walls," Geosynthetics International, vol. 24, no. 5, pp. 442-450, 2017.

[26] G. M. Latha and V. S. Murthy, "Effects of reinforcement form on the behavior of geosynthetic reinforced sand," Geotextiles and Geomembranes, vol. 25, no. 1, pp. 23-32, 2007.

[27] F. Song, H. Liu, B. Yang, and J. Zhao, "Large-scale triaxial compression tests of geocell-reinforced sand," Geosynthetics International, vol. 26, no. 4, pp. 388-395, 2019.

[28] M. Zhang, A. Javadi, and X. Min, "Triaxial tests of sand reinforced with 3D inclusions," Geotextiles and Geomembranes, vol. 24, no. 4, pp. 201-209, 2006.

[29] M. X. Zhang, H. Zhou, A. A. Javadi, and Z. W. Wang, "Experimental and theoretical investigation of strength of soil reinforced with multi-layer horizontal-vertical orthogonal elements," Geotextiles and Geomembranes, vol. 26, no. 1, pp. 1-13, 2008.

[30] J. Xue, Z. Liu, and J. Chen, "Triaxial compressive behaviour of geotextile encased stone columns," Computers and Geotechnics, vol. 108, pp. 53-60, 2019.

[31] J.-F. Chen, L.-Y. Li, J.-F. Xue, and S.-Z. Feng, "Failure mechanism of geosynthetic-encased stone columns in soft soils under embankment," Geotextiles and Geomembranes, vol. 43, no. 5, pp. 424-431, 2015.

[32] Y. Fu and C. B. Du, "Triaxial testing of geosynthetics reinforced tailings with different reinforced layers," Materials, vol. 13, no. 8, p. 1943, 2020.

[33] S. Q. Gui, Z. B. Zhu, Q. Li et al., "Design and construction of a 20-meter high reinforced soil retaining wall, geosynthetics in civil and environmental engineering," in Proceedings of the 4th Asian Regional Conference on Geosynthetics, pp. 342-345, Shanghai, China, June 2008. 
[34] A. Ekinci, M. Hanafi, and P. M. V. Ferreira, "Influence of initial void ratio on critical state behaviour of poorly graded fine sands," Indian Geotechnical Journal, vol. 50, no. 1, 2020.

[35] J. M. Duncan and C. Y. Chang, "Nonlinear analysis df stress and strain in soil," Journal of the Soil Mechanics and Foundations Division, vol. 96, no. 5, pp. 1629-1653, 1970.

[36] Z. J. Shen, "A nonlinear dilatant stress-strain model for soils and rock materials," Hydro-Science and Engineering, vol. 14, no. 4, pp. 1-14, 1986. 